\title{
Dual Effect of Central Injection of Recombinant Rat Interleukin-4 on Lipopolysaccharide- Induced Sickness Behavior in Rats
}

\author{
Rose-Marie Bluthé, Ph.D., Jacques Lestage, Ph.D., Gwen Rees, B.Sc., Ph.D., \\ Adrian Bristow, B.Sc., Ph.D., and Robert Dantzer, D.V.M., Ph.D.
}

Systemic administration of the bacterial endotoxin lipopolysaccharide (LPS) has profound depressive effects on behavior that are mediated by the inducible expression of pro-inflammatory cytokines, such as interleukin-1 (IL-1), IL-6 and tumor necrosis factor $\alpha$ (TNF), in the brain. To assess the regulatory effects of the anti-inflammatory cytokine IL-4 on LPS-induced sickness behavior, rats injected intra-peritoneally (i.p.) with LPS were administered intracerebroventricularly (i.c.v.) with IL-4. IL-4 (30 and $300 \mathrm{ng})$ potentiated the behavioral effects of
LPS $(175 \mu \mathrm{g} / 1000 \mathrm{~g})$ when both molecules were co-injected. However, when IL-4 (30 ng) was injected $12 \mathrm{~h}$ prior to LPS, it blocked the depressing effects of LPS on social exploration. These results indicate that the regulation of cytokine-induced sickness behavior by IL-4 can be either inhibitory or stimulatory depending on the sequencing of IL-4 and LPS treatments.

[Neuropsychopharmacology 26:86-93, 2002] (C) 2001 American College of Neuropsychopharmacology. Published by Elsevier Science Inc.
KEY WORDS: Cytokine; Interleukin-4; Lipopolysaccharide; Social behavior; Rat; Brain

When an organism becomes sick during the course of an infection, several changes occur, which are mediated by the central nervous system (CNS). These changes include regulated increases in body temperature, sleep, activation of the hypothalamo-pituitary-adrenocortical (HPA) axis, decreases in locomotor activity, feeding, drinking, and social interactions, and alterations in brain neuro-

From the Integrative Neurobiology Laboratory, INRA-INSERM U394, Institut François Magendie, Rue Camille Saint-Saëns, 33077 Bordeaux cedex, France (RMB, JL, RD), and Division of Endocrinology, National Institute for Biological Standards and Control, Blanche Lane, South Mimms, Potters Bar, Herts EN6 3QG, UK (GR, AB)

Address correspondence to: Rose-Marie Bluthé, Ph.D., INRAINSERM U394, Institut François Magendie, Rue Camille Saint-Saëns, 33077 Bordeaux cedex, France, Tel.: 335575737 16, Fax: 3355757

37 16, E-mail: rose-marie.bluthe@bordeaux.inserm.fr

Received December 19, 2000; revised May 8, 2001; accepted June 7, 2001.

Online publication: 6/14/01 at www.acnp.org/citations/Npp 06150101138. transmitters. They are due to the release of pro-inflammatory cytokines such as interleukin-1 (IL-1), IL-6 and tumor necrosis factor-alpha (TNF- $\alpha$ ) by activated monocytes and macrophages (Dantzer et al. 2001; Dinarello 2000; Gabay and Kushner 1999; Krueger et al. 1999; Mulla and Buckingham 1999; Rothwell 1997; Turrin and Plata-Salaman 2000). The same effects can be obtained by systemic administration of the cytokine-inducer lipopolysaccharide (LPS), a component of the cell wall of Gram-negative bacteria (Cabrera et al. 2000; Francis et al. 2000; Lacosta et al. 1999; Ma et al. 2000; MohanKumar et al. 2000; Roth and de Souza 2001; Swiergel and Dunn 1999; Yirmiya 1996; Yirmiya et al. 2001). Peripherally released cytokines act on the brain by inducing the expression and release of cytokines in the central nervous system (Eriksson et al. 2000; Konsman et al. 1999; Layé et al. 2000; Quan et al. 2000). LPS induces the expression of not only pro-inflammatory but also anti-inflammatory cytokines such as IL-10 and IL-13 in the brain (Wong et al. 1997). Another important antiinflammatory cytokine is IL-4. Although it is not syn- 
thesized in the normal brain (Lovett-Racke et al. 2000; Schluter et al. 1997), it is strongly expressed during brain injury, infection, experimental autoimmune encephalomyelitis, and neurodegenerative processes (Arsenijevic et al. 1998; Laman et al. 1998; Liedtke et al. 1998; Woodroofe and Cuzner 1993). Anti-inflammatory cytokines have the ability to suppress the synthesis of IL- $1, \mathrm{TNF}$, and other cytokines in peripheral immune and non-immune cells (Dinarello 1997; Marie and Cavaillon 1997).

There has been a recent surge of interest in the behavioral effects of cytokines in neuropsychopharmacology. Several reasons account for that, including the fact that cytokine-induced sickness behavior is not the result of weakness and physical debilitation but appears to be the expression of a previously unrecognized motivational state that is triggered by peripheral immune stimuli and reorganizes the organism's priorities (Dantzer 2001). In addition, the possibility of an intersection between sickness behavior and depression (Dantzer et al. 1999) has raised new and important issues in psychopathology.

If sickness behavior is the ineluctable result of the brain action of those proinflammatory cytokines that are released at the periphery during the course of an innate immune response or even in response to exteroceptive stressors, it becomes important to find out how this behavior is regulated. The production and action of proinflammatory cytokines at the periphery is primarily regulated by the so-called anti-inflammatory cytokines that include IL-10, IL-4 and IL-13. Little is know yet concerning the ability of these latter cytokines to oppose the development of sickness behavior. Using social withdrawal as a measure of sickness behavior, we have shown earlier that central administration of the antiinflammatory cytokine IL-10 attenuates the development of sickness behavior in rats injected with LPS at the periphery (Bluthé et al. 1999). The same model was used in the present study to assess the anti-inflammatory effect of IL-4. However, IL-4 blocked the depressing effect of LPS only when injected $12 \mathrm{~h}$ before the endotoxin treatment whereas it potentiated sickness behavior when injected at the same time than LPS. These results show that IL-4 can have pro- or anti-inflammatory effects depending on the sequencing of events.

\section{MATERIALS AND METHODS}

\section{Subjects}

Male Wistar Crl: (WI) IGS BR rats (125 -150 g) were obtained from Charles River, St-Aubin-lès-Elbeuf, France. After arrival at the facility, they were housed in groups of five in polypropylene cages and acclimated to the laboratory for at least two weeks. Room temperature was maintained at $23 \pm 1^{\circ} \mathrm{C}$, and lighting was main- tained on a 12-hr light/dark cycle (lights on at 2100). Food (Extralabo, Provins, France) and water were available ad libitum. Juveniles of the same strain served as stimulus animals and were housed in groups of 10 in a different room. The investigators adhered to the guidelines published in the NIH Guide for the Care and the Use of Laboratory Animals.

\section{Surgery}

For central injections, a stainless steel guide cannula (23-gauge, $7 \mathrm{~mm}$ length) was implanted unilaterally 1 $\mathrm{mm}$ above the lateral ventricle. For this surgery, rats were anesthetized intraperitoneally (i.p.) with a mixture of ketamine (Imalgene 1000, Rhône Mérieux, Lyon, France) and xylazine (Bayer Pharma, Puteaux, France), at doses of $61 \mathrm{mg}$ and $9 \mathrm{mg} / 1000 \mathrm{~g}$, respectively, and secured in a Kopf stereotaxic instrument (Tujunga, CA, USA). Coordinates were with toothbars $5 \mathrm{~mm}$ above the interaural zero, $0.6 \mathrm{~mm}$ posterior to the bregma, 1.5 $\mathrm{mm}$ lateral and $3.2 \mathrm{~mm}$ below the skull surface, at the point of entry (Paxinos and Watson 1986). At this point, the body weight was 160-200 g. Rats were allowed a 2-week recovery period before behavioral testing.

\section{Chemicals}

Recombinant rat interleukin-4 (IL-4) preparation: Messenger RNA (mRNA) was extracted from endotoxinstimulated rat monocytes using the QuickPrep mRNA Purification Kit (Pharmacia Biotech, 23 Grosvenor Road, St Albans, Hertfordshire AL1 3LW, UK). cDNA was transcribed using the First Strand cDNA synthesis kit (Pharmacia Biotech). PCR primers were designed to engineer the restriction sites Bgl II at the $5^{\prime}$ end and Xho I at the $3^{\prime}$ end of the rat IL-4 coding sequence respectively. Resultant PCR products were ligated into the vector pMT.BiP (Invitrogen, 3985B Sorrento Valley Boulevard, San Diego, CA 92121, USA) downstream of the metallothionein promoter (MT) and the immunoglobulin binding chaperone protein (BiP) Drosophila signal sequence. The $\mathrm{pMT}$.BiP/rat IL-4 vector was transformed into Escherichia coli strain JM109, where the construct was checked by restriction mapping followed by DNA sequencing. Drosophila S2 cells were stably co-transfected with $\mathrm{pMT} . \mathrm{BiP} / \mathrm{rat} \mathrm{IL}-4$ and the vector pCoHYGRO at a ratio of 19:1. Stable cell lines were grown in complete DES medium containing $800 \mu \mathrm{g} / \mathrm{ml}$ hygromycin-B (Invitrogen), hygromycin-resistant co-transfected cell lines took approximately three weeks to grow through, with a viability of $>95 \%$. One cell line was expanded into shake cultures $\left(24^{\circ} \mathrm{C}\right.$, shaking $\left.115 \mathrm{rpm}\right)$ in complete DES containing $300 \mu \mathrm{g} / \mathrm{ml}$ hygromycin-B and $0.05 \%$ Pluronic F-68 to prevent cell shearing. Cells were grown to a density of $10 \times 10^{6}$ cells $/ \mathrm{ml}$, centrifuged at $1000 \times \mathrm{g}$ for five minutes, the cell pellets washed twice with serum-free 
medium (containing 50 units/1 penicillin G, $50 \mu \mathrm{g} / 1$ streptomycin sulphate, $2 \mathrm{mM}$ L-glutamine and $0.05 \%$ Pluronic F-68), then re-suspended at a cell density of $6 \times$ $10^{6}$ cells $/ \mathrm{ml}$ and induced by the addition of $\mathrm{CuSO}_{4}$ to a final concentration of $500 \mu \mathrm{M}$. Cells were grown on for 8 days, $24^{\circ} \mathrm{C}$, shaking $115 \mathrm{rpm}$, then the medium harvested by centrifugation at $1000 \times \mathrm{g}$ for 10 minutes at $4^{\circ} \mathrm{C}$.

Recombinant rat IL-4 was purified using ion-exchange chromatography on SP-Trisacryl in $0.01 \mathrm{M}$ sodium phosphate, pH 6.0 (Sigma). Recombinant rat IL-4 was eluted with $0.05 \mathrm{M}$ sodium phosphate, $\mathrm{pH} 7.0$ containing $1.0 \mathrm{M}$ $\mathrm{NaCl}$. IL-4-containing fractions were pooled, trehalose added to $1 \mathrm{mg} / \mathrm{ml}$ and the preparation lyophilized. The lyophilized preparation was reconstituted in $2.5 \mathrm{ml}$ of Dulbecco's phosphate buffered saline (PBS) and large contaminating proteins removed by gel filtration on a Sephadex G75 column ( $450 \mathrm{ml}$ bed volume). Recombinant IL-4 eluted at V/Vt $=0.64-0.85$, IL-4 containing fractions were pooled and concentrated through a stirred cell membrane concentrator (Amicon). Endotoxin levels of recombinant rat IL-4 preparations ranged from $120-240 \mathrm{EU} / \mathrm{ml}(10 \mathrm{EU}=1 \mathrm{ng})$.

For central injections, recombinant rat IL-4 dissolved in $0.9 \%$ pyrogen free saline (SAL) was first injected in a volume of $2 \mu \mathrm{l}$ with a 30-gauge stainless-steel cannula, over a 30-sec period during which the rat was placed in a circular bowl. Control animals received SAL in the same conditions. Then, SAL or lipopolysaccharide (LPS, from Escherichia coli, Serotype 0127: B8, phenol extract, Sigma, St-Louis, MO, USA, L3129 - Horan et al. 1989) was injected into the peritoneal cavity (i.p.) at a dose of $175 \mu \mathrm{g} / 1000 \mathrm{~g}$ of body weight diluted in $2 \mathrm{ml}$ of sterile, pyrogen-free saline (SAL). At the conclusion of the experiment, cannula placement was verified by injecting a solution of India ink into the guide cannula and then slicing the brain after removal from the skull.

\section{Experimental Procedure}

Behavioral observations were carried out during the dark phase, between 9 A.M. and 5 P.M., using a video camera under red light illumination. Rats were isolated 24 hours before the experiment in transparent plastic cages $(30 \times 45 \times 19 \mathrm{~cm})$. Sickness behavior induced by LPS was assessed by decreases in duration of the injected adult's social exploration of a conspecific juvenile introduced into the home cage of the test animal. The observation procedure had been previously validated (Bluthé et al. 1992). One day before the experiment, baseline social exploration was assessed. The time spent by the experimental rat in social exploration, consisting of ano-genital sniffing, body sniffing and grooming of the juvenile, was measured during a 4-min period by using pre-set keys on the keyboard of an Apple Ile computer. The day after, rats were first injected, then tested with different juveniles on repetitions of the behavioral test at different time intervals. Two different series of experiments were carried out to assess the effects of IL-4 on LPS-induced sickness behavior.

\section{Experiment 1: Effect of Co-injections of i.c.v. IL-4 and i.p. LPS}

Forty rats were allocated to six treatment groups matched for mean baseline social exploration time and body weight: (i) i.c.v. SAL + i.p. SAL $(\mathrm{n}=7)$; (ii) i.c.v. SAL + i.p. LPS $(\mathrm{n}=8)$; (iii) i.c.v. IL-4 $(30 \mathrm{ng})+$ i.p. SAL $(\mathrm{n}=6)$; (iv) i.c.v. IL-4 (30 ng) + i.p. LPS ( $\mathrm{n}=7)$; (v) i.c.v. IL-4 (300 ng) + i.p. SAL (n = 5); (vi) i.c.v. IL-4 (300 ng) + i.p. LPS $(\mathrm{n}=7)$. The dose of LPS used $(175 \mu \mathrm{g} / 1000 \mathrm{~g})$ was selected so as to produce a decrease in social exploration which was not maximum (Bluthé, unpublished data). This dose caused obvious sickness symptoms, including immobility, shivering, and pilo-erection.

\section{Experiment 2: Effect of i.c.v. IL-4 Injected 12 Hours Prior i.p. LPS}

27 rats divided into three groups (matched for mean baseline social exploration time and body weight) were used in this experiment, and received (i) i.c.v. SAL + i.p. SAL $(\mathrm{n}=11)$ or (ii) i.c.v. SAL + i.p. LPS $(\mathrm{n}=7)$ or (iii) i.c.v. IL-4 (30 ng) + i.p. LPS $(n=9)$. The dose of IL-4 was the one that proved to be active in experiment 1 . Despite the fact that the dose of LPS was the same as in experiment 1, it produced a stronger effect in Experiment 2 , which can happen when working on different batches of rats.

For all the experiments, each rat received only one treatment combination. Behavior was monitored 2, 4, 6, and 24 hours after treatments.

\section{Statistical Analysis}

Experiment 1: Effects of Simultaneously Injected i.c.v. IL-4 and i.p. LPS. Duration of social exploration (sec) was analyzed by a two-way ANOVA with IL-4 (three levels: 0, 30 and $300 \mathrm{ng} / \mathrm{rat}$ ) and LPS (two levels: 0 and $175 \mu \mathrm{g} / 1000 \mathrm{~g}$ ) as between subject factors, and time (five levels: 0, 2, 4, 6 and 24 hours after treatment for social exploration) as a within subject factor. Post-hoc comparisons of individual group means were carried out by the protected least significant difference test (LSD).

Experiment 2: Effects of i.c.v. IL-4 Injected 12 Hours Prior to i.p. LPS. Duration of social exploration (sec) was analyzed by a two-way ANOVA with IL-4 (2 levels : 0 and $30 \mathrm{ng} / \mathrm{rat}$ ) and LPS (two levels : 0 and $175 \mu \mathrm{g} /$ $1000 \mathrm{~g}$ ) as between-subjects factors, and time (five levels: 0, 2, 4, 6 and 24 hours after treatment for social exploration) as a within-subject factor. Post-hoc compari- 
sons of individual group means were carried out by the protected least significant difference test (LSD).

\section{RESULTS}

\section{Experiment 1: Effects of Simultaneously Injected i.c.v. IL-4 and i.p. LPS on Behavior (Figure 1)}

A two-way ANOVA (treatment $X$ time) on duration of social exploration revealed significant effects of the main factors and their interaction $[\mathrm{F}(5,34)=5.7, p<$ $.001 ; \mathrm{F}(4,136)=16.3, p<.001 ; \mathrm{F}(20,136)=3.0, p<.001$, respectively]. Post-hoc comparisons of individual means by the LSD test revealed that i.c.v. IL-4 (30 ng) potentiated LPS-induced decrease in social exploration 2-6 hours after injection, and recovery was complete after 24 hours. In the same manner, i.c.v. IL-4 (300 ng) potentiated LPS-induced decrease in social exploration 2-4 hours after injection, and recovery was complete after 24 hours. However, the effect of IL-4 (30 ng) was more potent than that of IL-4 (300 ng) $2 \mathrm{~h}$ after injection on LPS-induced sickness behavior. Whatever the dose, IL-4
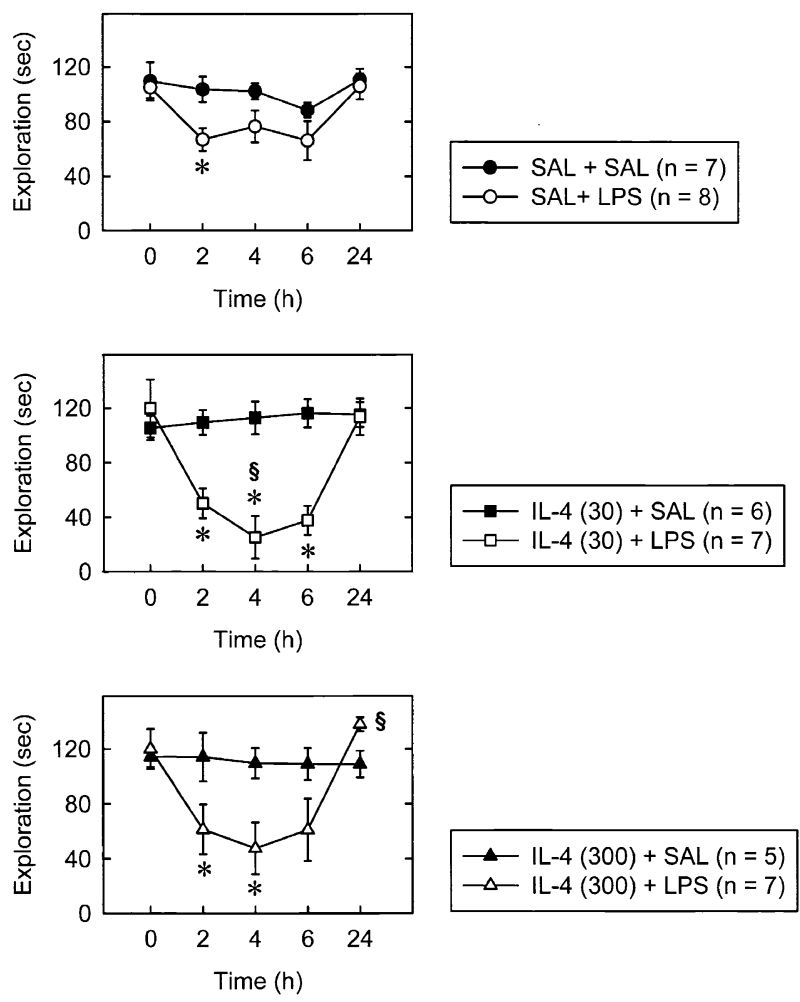

Figure 1. Effects of co-administration of i.c.v. recombinant rat interleukin-4 and i.p. LPS on social exploration. IL-4 (0, 30 , or $300 \mathrm{ng} / 2 \mu \mathrm{l})$ was injected i.c.v. just before i.p. LPS (0 or $175 \mu \mathrm{g} / 1000 \mathrm{~g} / 2 \mathrm{ml})$. Treatment effects were assessed on the mean duration of social exploration (sec) measured at time $2,4,6$ and 24 hours post-injection $\left[{ }^{*} p<.05\right.$ compared to SAL or IL-4 (30 or $300 \mathrm{ng})+\mathrm{LPS} ; \S p<.05$, SAL + LPS compared to IL-4 (30 or $300 \mathrm{ng})+\mathrm{LPS})]$ (mean \pm SEM). had no effect of its own on the duration of social exploration in saline-treated animals (Figure 1).

\section{Experiment 2: Effects of i.c.v. IL-4 Injected 12 Hours Prior to i.p. LPS (Figure 2)}

A two-way ANOVA (treatment $X$ time) on duration of social exploration revealed significant effects of the main factors and their interaction $[\mathrm{F}(2,24)=9.3, p<$ $.001 ; \mathrm{F}(4,96)=36.9, p<.001 ; \mathrm{F}(8,96)=16.8, p<.001$, respectively]. Post-hoc comparisons of individual means by the LSD test revealed that i.c.v. IL-4 (30 ng) blocked LPS-induced decrease in social exploration 2-4 hours after injection (Figure 2).

\section{DISCUSSION}

The results of the present study show that centrally administered IL-4 potentiates sickness behavior induced by systemic LPS when IL-4 is co-injected with LPS, whereas it attenuates the effects of LPS when administered $12 \mathrm{~h}$ before.

Peripherally administered LPS has been shown to induce the synthesis and release of proinflammatory cytokines in the brain (see Dantzer 2001 for a recent review). This local production of cytokines is responsible for the development and maintenance of sickness behavior, certainly by altering the metabolism of neurotransmitters including neuropeptides, although the exact mechanisms are still elusive (Dunn et al. 1999). The possibility that IL-4 is involved in the regulation of cytokineinduced sickness behavior has not yet been examined.
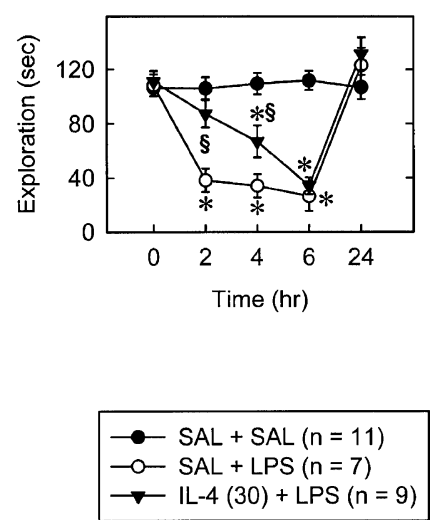

Figure 2. Effects of i.c.v. recombinant rat interleukin-4 injected 12 hours prior to injection of i.p. LPS on social exploration. IL-4 (0 or $30 \mathrm{ng} / 2 \mu \mathrm{l})$ was injected i.c.v. 12 hours before i.p. LPS (0 or $175 \mu \mathrm{g} / 1000 \mathrm{~g} / 2 \mathrm{ml})$. Treatment effects were assessed on the mean duration of social exploration (sec) measured at time 2, 4, 6 and 24 hours post-injection $\left[{ }^{*} p<.05\right.$ compared to SAL or IL-4 (30 ng) + LPS; $\$ p<.05$, SAL + LPS compared to IL-4 (30 ng) + LPS)] (mean \pm SEM). 
IL-4 is a pleiotropic cytokine produced by activated helper $\mathrm{T}$ cells which exerts multiple biological effects through binding to specific receptors on the cell surface (Mire-Sluis 1998; Nelms et al. 1999). Although IL-4 has initially been described as a B cell growth factor (Farrar et al. 1983), it has since been reported to regulate a wide range of immune responses, including increases in proliferation of B and T cells, enhancement of IgE synthesis, and up-regulation of the expression of class I and II HLA antigens (for reviews see Brown and Hural 1997; Paul 1991). IL-4 exerts its effects on cells of different lineages such as fibroblasts, endothelial cells (Lowenthal et al. 1988), microglia (Chao et al. 1993) and astrocytes (Brodie and Goldreich 1994; Pousset et al. 1999). IL-4 provides support for the development of humoral immune responses through the induction of T-helper type 2 (Th2) cell differentiation (Opal and DePalo 2000).

The anti-inflammatory action of IL-4 is well documented both in vitro and in vivo. IL-4 attenuates the activation of various immunocompetent cells, including neutrophils, monocytes and macrophages, by limiting the production of pro-inflammatory cytokines (Standiford et al. 1990; te Velde et al. 1990; Wertheim et al. 1993), and it decreases production of $\mathrm{PGE}_{2}$ (Niiro et al. 1997) and $\mathrm{O}_{2}^{-}$(Abramson and Gallin 1990; Maru and Jackson 1996). In a similar way, IL-4 limits the radiation-induced production of inflammatory mediators by endothelial cells (Van der Meeren et al. 1999b) and enhances survival of lethally irradiated mice (Van der Meeren et al. 1999a; Van der Meeren and Lebaron-Jacobs 2001). IL-4 plays an important role in modulating the severity of inflammation, as demonstrated by the use of IL4-deficient mice. These mice developed a more severe form of allergic encephalomyelitis and displayed a greater expression of pro-inflammatory cytokines in the CNS than their wild-type littermates (Falcone et al. 1998).

The attenuating effects of IL-4 on LPS-induced sickness behavior are in accordance with the anti-inflammatory properties attributed to this cytokine. The fact that IL-4 needs to be administered before the inflammatory challenge for its anti-inflammatory activity to show up is not uncommon. For example, i.p. IL-4 improved survival of mice infected systemically with lethal or sublethal inoculation of Pseudomonas aeruginosa when IL-4 treatment occurred 24 hours before challenge, and this treatment inhibited serum production of TNF- $\alpha$ (Giampietri et al. 2000). Identical responses were obtained in vitro on macrophage cultures. Moreover, the hyperalgesic response to IL- $1 \beta$ was inhibited by 30 to $74 \%$ by intraplantar IL- 4 when IL-4 was injected $12 \mathrm{~h}$ before IL$1 \beta$ whereas it had no effect when it was administered $30 \mathrm{~min}$ before IL-1 $\beta$ (Cunha et al. 1999). Exposure of murine peritoneal macrophages to murine IL- 4 for $16 \mathrm{~h}$ before stimulation with LPS inhibited LPS-induced production of prostaglandin $\mathrm{E}_{2}\left(\mathrm{PGE}_{2}\right)$ but not of IL-1 $\beta$. In the early phase of the hyperalgesic response, IL-4 inhibited the production of the hyperalgesic cytokines TNF- $\alpha$ and IL-1, whereas in the later phase of the hyperalgesic response, IL-4 inhibited COX-2 enzymes, since IL-4 given $12 \mathrm{~h}$ before IL-1 $\beta$, inhibited the hyperalgesic ef-

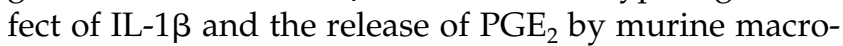
phages stimulated in vitro with LPS (Cunha et al. 1999). The anti-inflammatory effects of IL-4 can be explained by a decrease in the production of pro-inflammatory cytokines, certainly via inhibition of the nuclear transcription factor NFkappaB (Chao et al. 1993; Giampietri et al. 2000; Pousset et al. 1999).

The potentiation of LPS-induced sickness behavior by IL- 4 when both molecules were co-administered appears to be at odds with the anti-inflammatory activity of IL-4. Although the effects of LPS were less marked in the co-administration experiment than in the experiment in which LPS was injected $12 \mathrm{~h}$ prior to IL-4, this difference is unlikely to account for the present results. Differences in the magnitude of LPS effects are common between different batches of animals and are probably related to minor variations in the sanitary status of the population under test. In accordance with the observation of potentiating effects of IL-4 on LPS-induced sickness behavior, the results of a few reports indicate that IL-4 can exert pro-inflammatory effects. In vivo studies have demonstrated both positive and negative effects on the outcome of infectious diseases (Brown and Hural 1997; Jain-Vora et al. 1998). In particular, sublethally infected mice given IL-4 at the time of infection responded to this treatment with increased mortality and overproduction of TNF- $\alpha$ (Giampietri et al. 2000). Moreover, IL-4 administered $30 \mathrm{~min}$ before inhibited the hyperalgesia induced by bradykinin and TNF- $\alpha$ but not by IL-1 $\beta$ (Cunha et al. 1999). In vitro, IL-4 failed to inhibit LPS-induced production of IL-1 $\beta$ in cocultures of rat microglia and astrocytes (Ledeboer et al. 2000) and IL-6 in mouse primary astrocytes (Pousset et al. 1999), and it was able to enhance TNF- $\alpha$ (Giampietri et al. 2000) and IL-6 production (Pousset et al. 1999) under some conditions. The mechanisms of the potentiating effects of IL-4 on cytokine production and action are still unknown. In the context of the inflammatory response, IL-4 has been shown to upregulate the expression of adhesion molecules on vascular endothelial cells and promote the release of potent chemoattractants such as MCP-1, promoting the early recruitment of mononuclear cells to sites of tissue inflammation (Gundel et al. 1996). This effect could contribute to the potentiation of LPS-induced sickness behavior, by enhancing the normally discrete inflammatory response that develops in the brain in response to systemic LPS (Layé et al. 1994). In view of the importance of IL-1 $\beta$ in LPSinduced sickness behavior, another possibility is that IL-4 counteracts the down-regulatory effects of IL-1 on the expression of its active receptor, the IL- 1 type I receptor, 
and enhances the up-regulatory effects of IL- 1 on the expression of its decoy receptor, the IL-1 type II receptor, as indicated by in vitro studies (Pousset et al., in preparation). Whatever the mechanisms, the results of the present study indicate that IL-4, in contrast to IL-10, is unlikely to be a cytokine of choice for down-regulating the expression and action of pro-inflammatory cytokines in the brain.

\section{ACKNOWLEDGMENTS}

We thank the following individual and institutions: Olivier Debayle for help with experimental data; INRA, INSERM, and the European Community (Cybrainet, Biomed 2 CT972492) for financial support.

\section{REFERENCES}

Abramson SL, Gallin JI (1990): IL-4 inhibits superoxide production by human mononuclear phagocytes. J Immunol 144:625-630

Arsenijevic D, Girardier L, Seydoux J, Pechere JC, Garcia I, Lucas R, Chang HR, Dulloo AG (1998): Metabolic-cytokine responses to a second immunological challenge with LPS in mice with T. gondii infection. Am J Physiol (Endocrinol Metab) 274:E439-E445

Bluthé R-M, Dantzer R, Kelley KW (1992): Effects of interleukin-1 receptor antagonist on the behavioral effects of lipopolysaccharide in rat. Brain Res 573:318-320

Bluthé RM, Castanon N, Pousset F, Bristow A, Ball C, Lestage J, Michaud B, Kelley KW, Dantzer R. (1999): Central injection of IL-10 antagonizes the behavioural effects of lipopolysaccharide in rats. Psychoneuroendocrinology 24:301-311

Brodie C, Goldreich N (1994): Interleukin-4 modulates the proliferation and differentiation of glial cells. J Neuroimmunol 55:91-97

Brown MA, Hural J (1997): Functions of IL-4 and control of its expression. Crit Rev Immunol 17:1-32

Cabrera R, Korte SM, Lentjes EG, Romijn F, Schonbaum E, De Nicola A, De Kloet ER (2000): The amount of free corticosterone is increased during lipopolysaccharideinduced fever. Life Sci 66:553-562

Chao CC, Molitor TW, Hu S (1993): Neuroprotective role of IL-4 against activated microglia. J Immunol 151:1473-1481

Cunha FQ, Poole S, Lorenzetti BB, Veiga FH, Ferreira SH (1999): Cytokine-mediated inflammatory hyperalgesia limited by interleukin-4. Br J Pharmacol 126:45-50

Dantzer R (2001): Cytokine-induced sickness behavior: where do we stand ? Brain Behav Immun 15:7-24

Dantzer R, Bluthé R-M, Castanon-Faget N, Chauvet N, Capuron L, Goodall G, Kelley KW, Konsman J-P, Layé S, Parnet P, Pousset F (2001): Cytokine effects on behavior. In Ader R, Felten, DL, Cohen N (eds), Psycho- neuroimmunology. Vol 1, $3^{\text {rd }}$ ed. New York, Academic Press, pp 703-727

Dantzer R, Wollman EE, Vitkovic L, Yirmiya R (1999): Cytokines, stress and depression. Conclusions and perspectives. Adv Exp Med Biol 461:317-329

Dinarello CA (1997): Proinflammatory and anti-inflammatory cytokines as mediators in the pathogenesis of septic shock. Chest 112:321S-329S

Dinarello CA (2000): Proinflammatory cytokines. Chest 118:503-508

Dunn AJ, Wang J, Ando T (1999): Effects of cytokines on cerebral neurotransmission. Comparison with the effects of stress. Adv Exp Med Biol 461:117-127

Eriksson C, Nobel S, Winblad B, Schultzberg M (2000): Expression of interleukin- $1 \alpha$ and $\beta$, and interleukin-1 receptor antagonist mRNA in the rat central nervous system after peripheral administration of lipopolysaccharides. Cytokine 12:423-431

Falcone M, Rajan AJ, Bloom BR, Brosnan CF (1998): A critical role for IL-4 in regulating disease severity in experimental allergic encephalomyelitis as demonstrated in IL-4-deficient C57BL/6 mice and BALB/c mice. J Immunol 160:4822-4830

Farrar JJ, Howard M, Fuller-Farrar J, Paul WE (1983): Biochemical and physicochemical characterization of mouse B cell growth factor: a lymphokine distinct from interleukin-2. J Immunol 131:1838-1842

Francis J, MohanKumar SMJ, MohanKumar PS (2000): Correlations of norepinephrine release in the parenventricular nucleus with plasma corticosterone and leptin after systemic lipopolysaccharide: blockade by soluble IL-1 receptor. Brain Res 867:180-187

Gabay C, Kushner I (1999): Acute-phase proteins and other systemic responses to inflammation. $\mathrm{N}$ Engl J Med 340:448-454

Giampietri A, Grohmann U, Vacca C, Fioretti MC, Puccetti P, Campanile F (2000): Dual effect of IL-4 on resistance to systemic gram-negative infection and production of TNF- $\alpha$. Cytokine 12:417-421

Gundel R, Lindell D, Harris P, Fournel M, Jesmok G, Gerritsen ME (1996): IL-4 induced leucocyte trafficking in cynomolgus monkeys: correlation with expression of adhesion molecules and chemokine generation. Clin Exp Allergy 26:719-729

Horan MA, Little RA, Rothwell NJ, Strijbos PJ (1989): Comparison of the effects of several endotoxin preparations on body temperature and metabolic rate in the rat. Can J Physiol Pharmacol 67:1011-1014

Jain-Vora S, LeVine A-M, Chroneos Z, Ross GF, Hull WM, Whitsett JA (1998): Interleukin-4 enhances pulmonary clearance of Pseudomonas aeruginosa. Infect Immun 66:4229-4236

Konsman JP, Kelley KW, Dantzer R (1999): Temporal and spatial relationship between lipopolysaccharide-induced expression of Fos, interleukin-1 $\beta$ and inducible nitric oxide synthase in rat brain. Neuroscience 89:535-548

Krueger JM, Obal F Jr, Fang J (1999): Humoral regulation of physiological sleep: cytokines and GHRH. J Sleep Res 8:53-59

Lacosta S, Merali Z, Anisman H (1999): Behavioral and neu- 
rochemical consequences of lipopolysaccharide in mice: anxiogenic-like effects. Brain Res 818:291-303

Laman JD, van Meurs M, Schellekens MM, de Boer M, Melchers B, Massacesi L, Lassmann H, Claassen E, Hart BA (1998): Expression of accessory molecules and cytokines in acute EAE in marmoset monkeys (Callithrix jacchus). J Neuroimmunol 86:30-45

Layé S, Gheusi G, Cremona S, Combe C, Kelley KW, Dantzer R, Parnet P (2000): Endogenous brain IL-1 mediates LPS-induced anorexia and hypothalamic cytokine expression. Am J Physiol (Regulatory Integrative Comp Physiol) 279:R93-R98

Layé S, Parnet P, Goujon R, Dantzer R (1994): Peripheral administration of lipopolysacharide induces the expression of cytokine transcripts in the brain and pituitary of mice. Mol Brain Res 27:157-162

Ledeboer A-M, Brevé JJP, Poole S, Tilders FJH, Van Dam A$M$ (2000): Interleukin-10, interleukin-4, and transforming growth factor- $\beta$ differentialy regulate lipopolysaccharide-induced production of pro-inflammatory cytokines and nitric oxide in co-cultures of rat astroglial and microglial cells. Glia 30:134-142

Liedtke W, Cannella B, Mazzaccaro RJ, Clements JM, Miller $\mathrm{KM}$, Wucherpfennig KW, Gearing AJH, Raine CS (1998): Effective treatment of models of multiple sclerosis by matrix metalloproteinase inhibitors. Ann Neurol 44:35-46

Lovett-Racke AE, Smith ME, Arredondo LR, Bittner PS, Ratts RB, Shive CL, Forsthuber TG, Racke MK (2000): Developmentally regulated gene expression of $\mathrm{TH} 2$ cytokines in the brain. Brain Res 870:27-35

Lowenthal JW, Castle BE, Christiansen J, Schreurs J, Rennick D, Arai N, Hoy P, Takebe Y, Howard M (1988): Expression of high affinity receptors for murine interleukin-4 (BSF-1) on hemopoietic and nonhemopoietic cells. J Immunol 140:456-464

Ma XC, Chen LT, Oliver J, Horvath E, Phelps CP (2000): Cytokine and adrenal axis responses to endotoxin. Brain Res 861:135-142

Marie C, Cavaillon J-M (1997): Le rétrocontrôle négatif de l'inflammation: rôle des cytokines antiinflammatoires. Bulletin de l'Institut Pasteur 95:41-54

Maru A, Jackson SK (1996): Opposite effects of interleukin-4 and interleukin-10 on nitric oxide production in murine macrophages. Mediat Inflamm 5:110-112

Mire-Sluis AR (1998): Interleukin-4. In Mire-Sluis AR, Thorpe R (eds), Cytokines. New York, Academic Press, pp 53-68

MohanKumar SMJ, MohanKumar PS, Quadri SK (2000): Effects of bacterial lipopolysaccharide on central monoamines and fever in the rat: involvement of the vagus. Neurosci Lett 284:159-162

Mulla A, Buckingham JC (1999): Regulation of the hypothalamo-pituitary-adrenal axis by cytokines. Baillieres Best Pract Res Clin Endocrinol Metab 13:503-521

Nelms K, Keegan AD, Zamorano J, Ryan JJ, Paul WE (1999): The IL-4 receptor: signaling mechanisms and biologic functions. Annu Rev Immunol 17:701-738.

Niiro H, Otsuka T, Izuhara K, Yamaoka K, Oshima K, Tanaba T, Hara S, Nemoto Y, Tanaka Y, Niho Y (1997): Regulation by interleukin-10 and interleukin-4 of cyclooxygenase-2 expression in human neutrophils. Blood 89:1621-1628

Opal SM, DePalo VA (2000): Anti-inflammatory cytokines. Chest 117:1162-1172

Paul WE (1991): Interleukin-4: a prototypic immunoregulatory lymphokine. Blood 77: 1859-1870

Paxinos G, Watson C (1986): The rat brain in stereotaxic coordinates, $2^{\text {nd }}$ ed. New York, Academic Press

Pousset F, Cremona S, Dantzer R, Kelley KW, Parnet P (1999): Interleukin-4 and interleukin-10 regulate IL-1 $\beta$ induced mouse primary astrocyte activation: a comparative study. Glia 26:12-21

Quan N, He L, Lai W, Shen T, Herkenham M (2000): Induction of IкB $\alpha$ mRNA expression in the brain by glucocorticoids: a negative feedback mechanisms for immuneto-brain signaling. J Neurosci 20:6473-6477

Roth J, de Souza GEP (2001): Fever induction pathways: evidence from responses to systemic or local cytokine formation. Braz J Med Biol Res 34:301-314

Rothwell NJ (1997): Neuroimmune interactions: the role of cytokines. Brit J Pharmacol 121:841-847

Schluter D, Kaefer N, Hof H, Wiestler OD, Deckert-Schluter M (1997): Expression pattern and cellular origin of cytokines in the normal and Toxoplasma gondii-infected murine brain. Am J Pathol 150:1021-1035

Standiford TJ, Strieter RM, Chensue SW, Westwick J, Kasahara K, Kunkel SL (1990): IL-4 inhibits the expression of IL-8 from stimulated human monocytes. J Immunol 145:1435-1439

Swiergel AH, Dunn AJ (1999): The roles of IL-1, IL-6 and TNF $\alpha$ in the feeding responses to endotoxin and influenza virus infection in mice. Brain Behav Immun 13:252-265

Turrin NP, Plata-Salaman CR (2000): Cytokine-cytokine interactions and the brain. Brain Res Bull 51:3-9

Van der Meeren A, Gaugler M-H, Mouthon M-A, Squiban C, Gourmelon P (1999a): Interleukin-4 promotes survival of lethally irradiated mice in the absence of hematopoietic efficacy. Radiation Res 152:629-636

Van der Meeren A, Squiban C, Gourmelon P, Lafont H, Gaugler MH (1999b): Differential regulation by IL-4 and IL-10 of radiation-induced IL- 6 and IL-8 production and ICAM-1 expression by human endothelial cells. Cytokine 11:831-838

Van der Meeren A, Lebaron-Jacobs L (2001): Behavioural consequences of an $8 \mathrm{~Gy}$ total body iradiation in mice: regulation by interleukin-4. Can J Physiol Pharmacol 79:140-143

te Velde AA, Huijbens RJ, Heije K, De Vries JE, Figdor CG (1990): Interleukin-4 (IL-4) inhibits secretion of IL-1 $\beta$, tumor necrosis factor $\alpha$ and IL-6 by human monocytes. Blood 76:1392-1397

Wertheim WA, Kunkel SL, Standiford TJ, Burdick MD, Becker FS, Wilke CA, Gilbert AR, Strieter RM (1993): Regulation of neutrophil-derived IL-8: the role of prostaglandin E2, dexamethasone, and IL-4. J Immunol 151:2166-2175

Wong ML, Bongiorno PB, Rettori V, McCan SM, Licinio J (1997): Interleukin (IL) 1及, IL-1 receptor antagonist, IL10 , and IL-13 gene expression in the central nervous 
system and anterior pituitary during systemic inflammation: pathological implications. Proc Natl Acad Sci 94:227-232

Yirmiya R (1996): Endotoxin produces a depressive-like episode in rats. Brain Res 711:163-174
Yirmiya R, Pollak Y, Barak O, Avitsur R, Ovadia H, Bette M, Weilhe E, Weidenfeld J (2001): Effects of antidepressant drugs on the behavioral and physiological responses to lipopolysaccharide (LPS) in rodents. Neuropsychopharmacology 24:531-544 